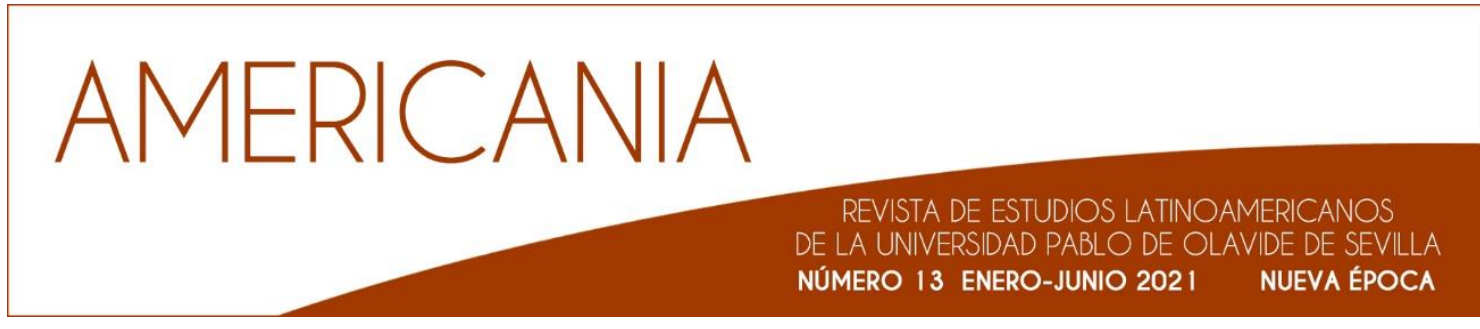

\title{
200 años de Independencia en el Perú, 200 años del Trienio Liberal en España
}

\author{
¿Qué conmemorar?
}

Juan Marchena Fernández

Director de Americanía. Revista de Estudios Latinoamericanos Universidad Pablo de Olavide

Imagen de Portada: Francisco 'Pancho' Fierro. "Negros chalas en el día del corpus", junio 1836. Acuarela sobre papel. 23×30.7 cm. Museo de Arte de Lima. Donación de Juan Carlos Verme.

Se conmemoran este mes de julio, el día 28, los 200 años de la proclamación por el general San Martín de la Independencia del Perú en la Plaza de Armas de Lima. Con su portada, nuestra revista quiere sumarse a esta conmemoración, no exenta de polémica, desde luego: una parte de la historiografía peruana se plantea la oportunidad de conmemorar otras fechas, como las de los movimientos insurgentes de 1810 a 1814, o la de la independencia proclamada en Trujillo a fines de 1820, o la de la batalla de Ayacucho en diciembre de 1824, cuando finalmente las tropas virreinales se rindieron a las patriotas... No son pocos los que achacan la elección de esta fiesta patria capitalina de julio de 1821 al hecho de haber sucedido en Lima y no en las provincias o en la Sierra.

A la vez, este mes de julio nos hallamos conmemorando en España el ecuador del Trienio Liberal (1 de enero 1820 a 1 de octubre de 1823) aquel movimiento revolucionario que reinstauró la Constitución gaditana de 1812 por la mano de 
Rafael del Riego y sus compañeros liberales, poniendo fin (aunque solo temporalmente) al régimen absolutista y represor de Fernando VII. La coincidencia en el tiempo de ambos procesos históricos, en Perú y en España, de ambos acontecimientos, nos lleva forzosamente a reflexionar sobre esta circunstancia: ¿ेfue coincidencia o fueron consecuencia uno de otro? Más coincidencia aún si pensamos que en 1821 alcanzaron también la Independencia México, Centroamérica, Panamá y Venezuela, y enseguida la que sería luego República del Ecuador a la que se uniría la actual Bolivia.

Por más leve que sea la mirada con que observemos el tiempo que aquí estudiamos, revuelto y cambiante, peligroso y bello, doloroso y sangriento como un parto, pero como él creador de una nueva realidad, como escribía el maestro Manuel Moreno Fraginals', repararemos que en él nos hallamos atrapados en una maraña de paradojas. Y entre todas ellas una muy evidente: durante el más recio y feroz y duro e intransigente absolutismo de Fernando VII, el conflicto de las colonias americanas con la metrópoli se zanjó con las independencias de Argentina (1816) Chile (1818) y Nueva Granada (1819), y además sujetas a la posibilidad de que la situación pudiera revertirse mediante una intervención militar; en cambio, durante el tiempo revolucionario del Trienio Liberal, 1820-1823, cuando revolucionariamente fueron restauradas las libertades en España, cuando se aseguró un marco garantista constitucional obligando por la fuerza al rey Fernando a jurar la Constitución, cuando se proclamó la hermandad universal de los liberales del mundo (desde España a Portugal, a Italia, a Grecia...), cuando se suponía que había de lograrse la paz, el acuerdo político en un marco ideológico común, una especie de gran confederación entre libres e iguales, fue entonces cuando la mayor parte de las colonias americanas, casi toda la América hispana, alcanzó la independencia de su metrópoli revolucionaria: como se indicó, México, Centroamérica, Panamá, Venezuela y Perú (en 1821), el Reino de Quito -Ecuador(1820-1822); y, además, fueron independencias ya irreversibles; y logradas en muchos casos tras una guerra en la que liberales a uno y otro lado del mar, españoles y americanos, acabaron quemándose como leña en el fuego. Revolución en España, guerra en América: qué paradoja.

Y otra más: este tiempo 1820-1824, que en la historiografía americana aparece y es tratado como un gozne fundamental en la historia, un 'nunca más la opresión',

1 Moreno Fraginals, Manuel, La historia como arma, y otros estudios sobre esclavos, ingenios y plantaciones, Critica, Barcelona, 1983, 22. 
'un viva la libertad' con mayúsculas, 'la base de la nación y la patria', en cambio en la mayor parte de la historiografía española este periodo del Trienio apenas figura sino como un episodio breve, apenas un trienio, el tiempo efímero de una revolución imposible, de un fracaso, un mal logro, un paréntesis (como alguien ha expresado), casi una excentricidad.

Visto lo anterior, la primera conclusión que podemos obtener es que se evidencia la necesidad de continuar estudiando este proceso bicontinental para explicarlo y explicárnoslo a cabalidad. La segunda es que este es un muy complicado asunto como para alcanzar rápidas, claras, sencillas y definitivas conclusiones. La tercera es que las historiografías respectivas deben ser revisadas, nuevas fuentes analizadas y nuevas miradas consideradas.

Porque, seguramente, este tiempo del Trienio en 'ambos hemisferios', como se leía en Cádiz, es mucho más largo que sus meros tres pocos años: desde luego no empieza en enero de 1820. Y es que, considero, no hay Trienio revolucionario en España sin 1808; como no hay Independencias en América en 1820-1824 sin incluir las revueltas, protestas, conspiraciones, rebeliones e insurgencias de 1809 a 1817 , por lo menos; y está por verse que no tengamos que considerar también los grandes movimientos sociales y étnicos de 1780 en adelante, que tanto polvo removieron y tanta sangre y tanto miedo produjeron. Una vez más, y volviendo a los viejos pero imprescindibles maestros, esto parece que solo se explica considerando los acontecimientos ocurridos durante el Trienio y las Independencias como parte de un proceso de larga duración.

Los combates sociales, las reivindicaciones apremiantes de muchos colectivos, tan diversos y heterogéneos, desarrolladas tanto en España como en América, contra un Antiguo régimen (llámese en América régimen colonial), caducado y en clara descomposición, la insurgencia contra las autoridades detentadoras del poder de este Antiguo régimen en América ya desmochado, su sustitución por nuevos agentes políticos, muchos de corte revolucionario, la importancia y los efectos de los ayuntamientos constitucionales y los procesos electorales que los conformaron a partir de Cádiz... todo ello forma parte precisa y fundamental de esta historia. No son acontecimientos, figuras, ideas, realidades escamoteables, a poco que ahondemos en el periodo, pero... qué poco las hemos considerado o nos las han hecho considerar. ¿¿ónde están? La guerra de 18201824, realizada por los principales gestores militares del periodo, y su magnificación, parece que se llevaron por delante todo lo anterior. 
Y surgen preguntas, muchas. Para los territorios americanos, que es lo que ahora me ocupa: Los actores sociales, económicos y étnicos que construyeron la médula del proceso revolucionario americano, desde 1810 en adelante iffueron sacados a bayonetazos o a golpe de tambor, a pura marcha militar, de la 'historia nacional' después de 1820? ¿ Fue la guerra la excusa perfecta para eso? Según una buena parte de las historiografías, española o americana, cada una en su ámbito, ¿́solo situamos los conflictos del periodo en los campos de batalla, bajo el sonoro rugir del cañón, o en el caracoleo de los caballos de los generales en las plazas?

Es verdad que con la guerra (las guerras, porque fueron un haz de ellas) se hizo avanzar a las Independencias como nunca antes, como se comprueba con la mera observación de las fechas de su consecución. Pero ¿̇dónde quedó todo lo demás, los combates sociales, las reivindicaciones colectivas, las exigencias de mayor participación y representación, los nuevos liderazgos revolucionarios surgidos contra las autoridades tradicionales, los reclamos étnicos, las peticiones de justicia y libertad, las elecciones, todo, todo lo que hasta entonces había constituido el corazón y el tronco de las insurgencias anticoloniales sucedidas revolucionariamente hasta entonces? ¿Se las llevaron las guerras en su turbamulta? ¿Tuvieron las guerras, que conocemos y nos han explicado hasta en sus más íntimos detalles, algo o poco o mucho de contrarrevolucionarias? ¿Por qué nos falta tanto por estudiar y conocer de todo el periodo anterior entre 1809 y 1820 ? ¿Qué justifica esta ausencia?

Lo cual nos lleva a la pregunta que otro maestro, Jorge Basadre, nos hiciera años atrás, nada menos que en 1973, refiriéndose al Perú y que quedó sin respuesta:

"¿Optamos por la revolución de 1814-1815 o por la de 1820-1824? ... Entre la revolución surgida entre 1820 y 1824 y la de 1814, preferimos esta última. En el caso de haber logrado ella sus objetivos máximos, para lo cual le faltaron... un conjunto de probabilidades objetivas, habría surgido un Perú nacional [unos Andes, añadimos nosotros] sin interferencias desde afuera y con una base mestiza, indígena, criolla y provinciana"2.

Mucho más recientemente, Erick Van Young en La otra Revolución...3, Juan Ortiz Escamilla en Guerra y gobierno ${ }^{4}$... o Manuel Chust en Las Juntas y la

2 Basadre, Jorge, El azar en la historia y sus límites. Con un Apéndice: La serie de probabilidades dentro de la emancipación peruana, Ediciones P.L.V., Lima, 1973.

3 Van Young, Eric, La otra rebelión. La lucha por la independencia de México, 1810-1821, FCE, México, 2006.

4 Ortiz Escamilla, Juan, Guerra y gobierno. Los pueblos y la Independencia de México, 1808-1825, El Colegio de México - Instituto Mora, México, 2014. 
revolución5, cuando analizan 'la rebelión de los pueblos', plantean cuestiones similares para México en 1810-1821.

Y tras esa pregunta del maestro Basadre, y como consecuencia de la misma, surge otra cuestión que ahora debemos plantearnos: ¿̇Dónde estaban en 1820-1824 los actores revolucionarios de 1809-1817, es decir, las 'repúblicas de indios', los 'libres de todos los colores', los esclavizados, los 'arrochelados en armas', el 'común de los barrios', las 'autoridades de comunidad o ayllu', 'los pueblos', 'los guerrilleros', 'los alzados', los insurgentes, en resumen... hombres, mujeres (muchas) de las ciudades y los campos, de los pueblos en rebelión, como escribió Juan Ortiz, que tanta importancia tuvieron en esos años capitales del inicio del proceso? Y me sigo preguntando: ¿¿Dónde habían quedado todos ellos en 1820 ? ¿Dónde habíamos perdido a los sans-culottes americanos, sin gorro frigio, pero con poncho, roana, manta, huipil, vestido, calzón, alpargatas, huaraches, chancletas, ojotas, camisa, anaco...? ¿ ¿Dónde estaban en 1820-24, cuando solo encontramos en los textos soldados y oficiales, granaderos, húsares, generales, coroneles, edecanes, artilleros, morriones, casacas, charreteras, botas de montar, polainas, correajes, cartucheras... marchando a paso de vencedores? Para los patriotas, ¿̇vencer en la guerra a los realistas significaba el triunfo de la revolución planteada y peleada unos años antes? $\dot{2} \mathrm{O}$, siguiendo a Basadre, estamos ahora, en 1820-1824, ante una revolución diferente? ¿ $\mathrm{O}$ ante una contrarrevolución?

Ciertamente no hallamos en 1820 a los actores revolucionarios anteriores, o al menos no los hallamos como antes. Considerando lo sucedido en el periodo álgidamente insurgente y claramente revolucionario de 1809-1817, por lo menos en los Andes pero que podría extrapolarse a otros lugares, convenimos en que la participación popular había sido muy vigorosa, amplia, poderosa, diversa, interviniendo en los procesos los más variados sectores sociales y sus dirigencias, fuese gente de los barrios de las ciudades en Lima, Trujillo, Arequipa, Cusco, Quito, Cuenca, Guayaquil, Puno, La Paz, Cochabamba, Potosí, Chuquisaca o Tarija; o de pueblos y comunidades indígenas con sus autoridades étnicas o del ayllu al frente, en tantos y tantos lugares de la geografía andina, como en Tacna, Arica $u$ Ocongate; o sectores de las élites criollas o mestizas en las haciendas, en los pueblos y ciudades; o grupos armados en guerrilla a medio camino entre el bandidaje y el patriotismo, como en Cochabamba, Paria o Cangallo...

5 Chust Calero, Manuel, Las juntas y la revolución en el mundo hispano. 1808-1810. Guerra, revolución, constitución, Universitat de València, Valencia, 2012. 
En 1810, en el Alto Perú, la actual Bolivia, un buen número de indígenas con sus caciques y autoridades al frente, en una clara insurgencia revolucionaria, proclamaban querer acabar con los blancos y regresar al tiempo en que "reinaran los indios", quienes "habrían de quedar dueños absolutos de estos lugares, como también de los caudales"6 (véanse los casos de Oruro, Cochabamba, la Paz, sitiando ciudades, quemando haciendas), que tantos ecos traía de 1780, una casi repetición de las soflamas, asaltos e incendios de Amarus y Kataris7. Y coincidiendo con los anteriores, hallamos otros movimientos de mayor escala, como los de Huánuco, o los liderados por los Angulo, o por Mateo Pumacahua, que incendiaron buena parte de la región. Muchas veces se olvida el sitio, toma y saqueo de La Paz por los insurgentes, en su mayor parte indígenas, en 1814, donde se mostró la naturaleza étnica del conflicto, claramente revolucionaria, y que llevó al general realista Ramírez cuando retomó la ciudad a escribir:

"Inflamada la multitud, se arroja precipitada sobre las prisiones; cada uno, como león irritado y furioso, se abalanza sobre su presa, la despedaza y la devora. De tantas inocentes víctimas, ninguna se salva. Todas perecen con mil muertes distintas, a cual más bárbaras y atroces... algunos patricios, la mayor parte europeos y españoles de la primera distinción: ni la memoria de sus beneficios, ni el sacrificio de sus caudales... ni los sagrados vínculos de la naturaleza y de la amistad, ni una virtud, en fin, sólida, pura y acrisolada en cuarenta años de residencia, salvó a ninguno de las garras de aquellos tigres cebados y sedientos de humana sangre... Arroyos de sangre corrían por las plazas entre los mutilados y palpitantes cadáveres"8.

Eran los efectos de la revolución, con todas las letras, el horror, el terror de las elites blancas.

Y sumemos a lo anterior, ahora en clave política pero no menos revolucionaria por sus efectos, las elecciones convocadas, como un resultado de Cádiz, en casi toda la región andina entre grandes colectivos de población en 181213, que tanto conmocionaron aquel mundo, con el triunfo y proclamación de

6 Thomson, Sinclair, Cuando solo reinasen los indios. La política aymara en la época de la insurgencia, La Mirada Salvaje, La Paz, 2010, 308.

7 Soux, María Luisa, El complejo proceso hacia la independencia de Charcas (1808-1826) Guerra, ciudadanía, conflictos locales y participación indígena en Oruro, ASDI- IFEA- Plural- IEB, La Paz, 2010.

8 "Diario de la expedición del mariscal de campo Juan Ramírez", citado por Soux, María Luisa, "La violencia y el miedo a los indios durante el proceso de Independencia. El caso de los cercos a la Paz en 1811 y 1814", en Manuel Chust y Claudia Rosas, Los miedos sin patria, Temores revolucionarios en las Independencias Americanas, Silex, Madrid, 2019, 575. 
nuevas dirigencias en los cabildos y pueblos de indios, casi liquidando el poder de los caciques tradicionales, de las viejas autoridades, pero también en ciudades grandes como Cusco y sus barrios (San Jerónimo, San Sebastián, Belén). Nuevos y viejos liderazgos que transformaron o estaban en vías de transformar aquel mundo, luego prohibidos en 1815, y en 1820 recompuestos pero desatendidos, ignorados, si no desestimados o excluidos, y vueltos a prohibir en 1823...

Desestimados y excluidos no solo por los constitucionalistas españoles y sus representantes en América, en sus vaivenes políticos, sino también por los líderes militares independentistas.

Sirva como ejemplo el episodio que estudió el maestro Waldemar Espinoza', sucedido en Cajamarca en enero 1821, cuando tras decretarse la independencia de Trujillo y su jurisdicción, en mitad del acto solemne de proclamación presidido por los grupos blancos de la región, todos de relucientes uniformes, aparecieron sin ser convocados (obviamente), los caciques principales de las Siete Huarangas de la provincia de Cajamarca y los dos alcaldes del Cabildo de Naturales de la ciudad, junto con los representantes de las dos principales panacas incaicas aún existentes en la provincia, los Astopilco y los Astoquipan, descendientes de los Carguarayco, y éstos de los reyes Chuquimancu y Cuismancu, entroncados con Túpac Inca Yupanqui y Huayna Cápac, con todo su ceremonial, sus símbolos e insignias. Pidiendo el uso de la palabra, expusieron ante la endomingada y sorprendida concurrencia, en un solemne discurso, el hecho de ser descendientes de Atahualpa y que, por lo tanto, se hallaban acreditados para ocupar el gobierno del nuevo estado independiente, siendo de toda justicia devolver el poder perdido con la conquista a sus verdaderos herederos, los Incas. Mostraban, desde luego, su mejor disposición a acordar con las autoridades presentes las nuevas medidas a adoptar, especialmente liberar a los comuneros e indígenas de la prestación de muchos servicios y tributos abusivos a los que estaban sometidos por las autoridades, proponiendo finalmente la restauración del Tahuantinsuyo y exponiendo con énfasis su derecho a la corona del mismo. No pudieron terminar su alegato: el gobernador militar, bastante irritado por la interrupción y el tono altanero 'de aquellos indios', solo les prometió elevar su propuesta al recién nombrado presidente, el marqués de Torre Tagle, tras lo cual los representantes de la nobleza originaria abandonaran la

9 Espinoza Soriano, Waldemar, "Reacción de los indígenas de Cajamarca frente a la Independencia de Trujillo y Lima, 1821-1822", en Revista Investigaciones Sociales, Lima, Universidad Nacional Mayor de San Marcos, 2000, 179-220. 
sala, prosiguiendo la ceremonia oficial, es de imaginar que entre suspiros de alivio por parte de los presentes. Nadie respondió jamás a estas autoridades indígenas, pero quedó claro que su propuesta estaba muy lejos, como cita Espinoza, del discurso político de los ideólogos de la independencia de Trujillo y del Perú en su conjunto. A aquellos generales blancos, coroneles, mariscales de campo, todos entorchados, de sables ruidosos y botas lustrosas, ni se les pasaba por la cabeza que los Incas constituyeran o pudieran constituir una alternativa de gobierno. Al advertir que no les hacían el menor caso, los representantes de la nobleza indígena cajamarquina comprendieron que ni las 'reformas liberales' ni la guerra, a partir de 1820, iban con ellos.

En el Cusco, como han demostrado Carmen Escalante y David Garrett10, sucedió algo similar: a pesar de que las principales familias Incas habían colaborado (si acaso en el último momento) con los jefes del ejército patriota, fueron luego ninguneados y relegados por las nuevas autoridades militares que ocuparon el poder tras la guerra, como demuestra la correspondencia de las panacas incaicas con Bolívar, Gamarra, Santa Cruz y sus oficiales. A los pocos días de la victoria de Ayacucho, el general Agustín Gamarra entró triunfal en el Cusco representando a los Libertadores, entre arcos, banderas, fanfarrias y nubes de mistura, nombrándose la primera corporación municipal republicana, que enseguida reconoció la Independencia del Perú entre gritos de viva la patria y la libertad. Como señala Nuria Sala'11, en ella todos eran miembros de la élite cusqueña blanca y mestiza. Ningún indígena. El Cabildo de Indios nunca fue reinstaurado, ni sus miembros volvieron a desfilar cívicamente. La nobleza indígena, los Incas y sus panacas, las autoridades de San Jerónimo o San Sebastián, fueron desconocidas o suplantadas. La élite señorial indígena, que un papel tan protagónico había tenido hasta entonces, quedaba como objeto de curiosidad para viajeros extranjeros, concluye Sala.

¿No parece este periodo 1820-1824, marcado por la guerra, absolutamente diferente en lo político y lo ideológico al anterior de 1809-1817, cuando se habían producido importantes cambios en la región, producto muchos de ellos de

10 Escalante, Carmen, "Rugido alzado en armas. Los descendientes de Incas y la independencia del Perú. Las rebeliones de José Gabriel Tupa Amaru, los hermanos Angulo y Mateo Pumaccahua, a partir de la documentación inédita de los Tupa Guamanrimachi Ynga. Cusco, 1776-1829", Tesis Doctoral defendida en la Universidad Pablo de Olavide, Sevilla, 2017; Garrett, David T., Sombras del Imperio. La nobleza indígena del Cuzco, 1750-1825, IEP, Lima, 2009.

11 Sala i Vila, Nuria, "El Trienio Liberal en el Virreinato peruano: los ayuntamientos constitucionales de Arequipa, Cusco y Huamanga, 1820-1824", Revista de Indias, 2011, vol. LXXI, núm. 253, 723. 
movimientos revolucionarios? ¿ ¿Fue, por tanto, la revolución en la península, el Trienio Liberal, el catalizador principal para que se produjera la eclosión final de la independencia de muchas regiones americanas, y en especial de la región andina, tras una guerra definitiva? ¿ No resultó sustituida, tras varios intentos de extender el liberalismo constitucional español (intentos fracasados y llevados a cabo por militares y no por políticos, no hay que olvidarlo) producto de la revolución peninsular a los territorios americanos, por una declaración de guerra, enviando desde España más tropas para someter a los insurgentes, apretando más aún el lazo de las hostilidades? ¿ ${ }^{N o}$ tuvo esta guerra entre liberales de parecido espíritu y similares orígenes y casi idénticas formas, unos peninsulares otros americanos, unos 'nacionales' otros 'patriotas', militares todos, el efecto de sofocar los movimientos anteriores, desde 1810, que habían conformado el verdadero espíritu revolucionario en los territorios americanos, en cuanto no formaban parte del objetivo común de ganar esa guerra, y porque resultaban 'peligrosos' e 'inconvenientes' para ambos? $\dot{\iota}^{N}$ o vino a servir ahora la guerra, por ambas partes aplicada con contundencia, y sobre todo su final, para liquidar y someter y detener a la revolución, a los cambios sociales, políticos, ideológicos que se habían venido sucediendo (y vuelvo con especial énfasis a la región andina) fundamentalmente de la mano de sectores populares, indígenas y no indígenas, y que, caso de haber triunfado, habrían originado drásticas trasformaciones políticas y sociales en el continente, que ninguno de los dos bandos admitiría?

¿O acaso no fue ésta una de las consecuencias de la multiplicación de la guerra en los Andes: el fin de lo que iba tratando de ser una revolución en los años precedentes, en los campos y en los barrios de las ciudades, con sus propios líderes, sus propios idearios, su profundo y radical discurso étnico, ininteligible o muy peligroso para las élites blancas realistas o patriotas, en cuanto se basaba en expulsarlas de sus prerrogativas, sus privilegios, sus inmunidades, su omnímodo poder sobre los demás sectores, en especial indígenas, negros, mulatos, mestizos, esclavizados? ¿ ¿No vino a resultar esta revolución imposible (como consecuencia de una guerra convencional planteada entre 'patriotas' y 'nacionales') e inviable, siendo sustituidas sus razones, sus argumentos, sus medidas, por otras que tenían dueño, forma, color de uniforme y hasta música de bandas castrenses? ¿̇No vino, finalmente por parte de unos y otros, a ser aprovechada la guerra para liquidar, someter, invisibilizar a los auténticos actores y gestores de los movimientos de años anteriores, especialmente a las poblaciones indígenas, mestizas y pardas o negras, 
a las esclavizadas, y a sus liderazgos, que con la fuerza del grito y el tizón encendido elevaban reclamos muy peligrosos para el establecimiento de un 'nuevo orden', fuese liberal constitucionalista o liberal independentista, y que sí contenían un ideario revolucionario y una agenda de grandes cambios? Muchas preguntas en este tiempo de bicentenarios que tenemos que aprovechar para conocer más e intentar responderlas.

Convendremos en que, si nos situamos en América en el momento de 1820, y con las noticias llegadas desde Madrid proclamando el fin del absolutismo y la conquista definitiva de la libertad, estaríamos tentados de pensar que el mundo antiguo iba a saltar por los aires, que estábamos ante el triunfo de la revolución. Pero no fue así. Parece como si la revolución, a nivel continental, hubiera sido sometida a partir de entonces a las leyes de una confrontación armada convencional, que un grupo de uniformados e iluminados por la guerra, de ideas afines aunque banderas diferentes, tanto en un bando como en otro, realistas o patriotas, se encargaron de llevar a cabo. Mientras proclamaban actuar en procura de la libertad, las consecuencias de sus actuaciones, políticas y militares, fueron en cambio, bien diferentes, y bien conocidas que son por todos y todas nosotras/os.

Como escribía Basadre, con el triunfo en América de la opción militarista de 1820 a 1823, frente a la revolucionaria de 1808-1817, se perdió la posibilidad de lograr una independencia más 'nacional', con menos interferencias militares, y con una base mestiza, indígena, criolla y provinciana mucho más sólida e incluyente social y políticamente. Y desde luego los esclavizados/as hubieran alcanzado la libertad como mínimo cincuenta años antes.

Doscientos años después de la fecha que conmemoramos, parece que estamos en lo mismo. Como si siguiéramos en la pelea por la consecución de una Independencia, una vez más, 'mestiza, indígena, criolla y provinciana'. En España, mientras, y en cambio, la posibilidad revolucionaria de 1820-23 fue ahogada por otro turbión de cañonazos, invasiones y absolutismos militares. Por décadas, casi por siglos. Ojalá que no estemos también en lo mismo, aunque algunos parezcan vivir más cómodos en este pasado sangriento y obscuro que en una realidad democrática colectiva e inclusiva. Por eso es más necesario que nunca ahondar en este proceso que estudiamos, rescatando para la memoria a las y a los excluidos de esta historia. 


\section{Referencias Bibliográficas}

Basadre, Jorge, El azar en la historia y sus límites. Con un Apéndice: La serie de probabilidades dentro de la emancipación peruana, Ediciones P.L.V., Lima, 1973.

Chust Calero, Manuel, Las juntas y la revolución en el mundo hispano. 1808-1810. Guerra, revolución, constitución, Universitat de València, Valencia, 2012.

Escalante, Carmen, "Rugido alzado en armas. Los descendientes de Incas y la independencia del Perú. Las rebeliones de José Gabriel Tupa Amaru, los hermanos Angulo y Mateo Pumaccahua, a partir de la documentación inédita de los Tupa Guamanrimachi Ynga. Cusco, 1776-1829”, Tesis Doctoral defendida en la Universidad Pablo de Olavide, Sevilla, 2017.

Espinoza Soriano, Waldemar, "Reacción de los indígenas de Cajamarca frente a la Independencia de Trujillo y Lima, 1821-1822”, en Revista Investigaciones Sociales, Lima, Universidad Nacional Mayor de San Marcos, 2000.

Garrett, David T., Sombras del Imperio. La nobleza indígena del Cuzco, 1750-1825, IEP, Lima, 2009.

Moreno Fraginals, Manuel, La historia como arma, y otros estudios sobre esclavos, ingenios y plantaciones, Critica, Barcelona, 1983.

Ortiz Escamilla, Juan, Guerra y gobierno. Los pueblos y la Independencia de México, 1808-1825, El Colegio de México - Instituto Mora, México, 2014.

Sala i Vila, Nuria, "El Trienio Liberal en el Virreinato peruano: los ayuntamientos constitucionales de Arequipa, Cusco y Huamanga, 1820-1824", Revista de Indias, 2011, vol. LXXI, núm. 253.

Soux, María Luisa, El complejo proceso hacia la independencia de Charcas (1808-1826) Guerra, ciudadanía, conflictos locales y participación indígena en Oruro, ASDIIFEA- Plural- IEB, La Paz, 2010.

Soux, María Luisa, "La violencia y el miedo a los indios durante el proceso de Independencia. El caso de los cercos a la Paz en 1811 y 1814", en Manuel Chust y Claudia Rosas, Los miedos sin patria, Temores revolucionarios en las Independencias Americanas, Silex, Madrid, 2019.

Thomson, Sinclair, Cuando solo reinasen los indios. La política aymara en la época de la insurgencia, La Mirada Salvaje, La Paz, 2010.

Van Young, Eric, La otra rebelión. La lucha por la independencia de México, 1810-1821, FCE, México, 2006. 